\title{
Diş Hekimliğinde Yeni ve Hızla İlerleyen Üretim Teknolojisi: 3 Boyutlu Yazıcılar
}

\author{
New and Rapidly Progressing Manufacturing Technology in \\ Dentistry: 3 Dimensional Printers
}

Esra YAVUZ, Selmi YILMAZ

Akdeniz Üniversitesi Diş Hekimliği Fakültesi, Ağ̣z Diş ve Çene Radyolojisi Anabilim Dal, Antalya, Türkiye

Yazışma Adresi

Correspondence Address

\section{Esra YAVUZ}

Akdeniz Üniversitesi Diş Hekimliği

Fakültesi, Ağız Diş ve Çene

Radyolojisi Anabilim Dalı, Antalya,

Türkiye

E-posta: esrsrt89@gmail.com

Geliş tarihi \Received : 21.02 .2020 Kabul tarihi \ Accepted : 29.05.2020 Elektronik yayın tarihi $\quad: 12.07 .2021$ Online published

Bu makaleye yapılacak atıf: Cite this article as:

Yavuz E, Yılmaz S. Diş hekimliğinde yeni ve hızla ilerleyen üretim teknolojisi: 3 boyutlu yazıcılar. Akd Tip D 2021; 7(2):197-205

Esra YAVUZ

ORCID ID: 0000-0003-3455-2586

Selmi YILMAZ

ORCID ID: 0000-0001-9546-6548
ÖZ

Üretim teknolojilerindeki hızlı gelişim ve 3 boyutlu yazıcıların bulunması ile diş hekimliği pratiğinde önemli değişiklikler gündeme gelmiştir. 3 boyutlu yazıcıların kullanıldığı bu yeni teknoloji; geleneksel üretimin aksine, daha hızlı ve düşük maliyetli üretim imkânı sunmaktadır. Ayrıca hastaların; birden fazla randevu gerektiren diş tedavi işlemlerine, tek seansta, kişiye özel tasarımlarla ve zengin materyal seçenekleriyle ulaşabilmelerini sağlayacaktır. 3 boyutlu yazıcılarla üretimin diş hekimliği pratiğine girmesiyle büyük bir devrim yaşanacaktır. Bu derlemeyi hazırlamaktaki amacımız 3 boyutlu yazıcılara dair genel bir bakış sağlamaktır. Ayrıca okuyuculara; aşındırıcı ve eklemeli üretim teknolojileriyle, bu teknolojilerin tarihçesi, avantaj ve dezavantajları ve diş hekimliği pratiğinde nasıl kullanıldığına dair bilgi verilmesi amaçlanmıştır.

Anahtar Sözcükler: CAD-CAM, Diş hekimliği teknolojisi, Stereolitografi, 3-Boyutlu yazıcı, 3B yazic1

\begin{abstract}
With the rapid development in manufacturing technologies and the invention of 3 dimensional printers, important changes in the practice of dentistry have come into question. This new technology using 3 dimensional printers; unlike conventional manufacturing, it provides faster and lower cost manufacturing. In addition, patients; It will enable them to access dental treatments that require more than one appointment, in a single visit, with individual designs and rich material options.

There will be a great revolution with the manufacturing of 3 dimensional printers in the practice of dentistry. Our aim in preparing this review is to provide an overview of 3 dimensional printers. In addition, it is aimed to give information to the readers about subtractive and additive manufacturing technologies and also the history, advantages and disadvantages of these technologies and how they are used in dental practice.
\end{abstract}

Keywords: CAD-CAM, Dental technology, Stereolithography, 3-Dimensional printing, 3D printing

\section{TARİHÇE}

18. yüzyılda sanayi devrimi ile üretim yapısında ve ülkelerin ekonomilerinde büyük ve köklü değişimler yaşanmıştır. Bu döneme kadar tüm üretim sistemleri el ile kontrol ediliyordu. El ve beden gücü ile üretim, bu dönemde yerini buharlı makinelere birakmıştır. 19. Yüzyılda II. Sanayi devriminin yaşandığı dönemde ise, üretimde elektrik kullanımı başlamış sonrasında da yaygınlaşmıştır. Ayrıca bu yıllarda Henry Ford'un önderlik ettiği bant üretim sistemi kullanılmaya başlanmıştır (1). 1948 yılında Frank L. Sluten ve John L. Pearson sayısal kontrollü Numerical Control (NG) tezgahlarını icat etmişlerdir. Bugün Computer Numerical 
Control (CNC) olarak bilinen makinenin atası bu icattır. CNC, makineler üzerine monteli bir bilgisayar aracıllŏg ile programlanarak işlem yapılan tezgahlardır (2). Bu gelişmelerden sonra Bilgisayar Destekli Tasarım / Bilgisayar Destekli Üretim (Computer Aided Design / Computer Aided Manufacturing, CAD/CAM) üretim teknolojilerine katılmıştır. 1970'li yllarda Duret ve Preston tarafindan CAD/CAM diş hekimliği pratiğine dahil edilmişstir (3).

Eklemeli üretim teknolojisi ile hayatımıza giren 3 boyutlu yazıcıların hikayesi, Dr. Kodama ile başlamıştır. Dr. Kodama, bulduğu teknikle 1980 yılında patent başvurusu yapmıştır. Fakat çeşitli nedenlerle patent alamamıştır $(4,5)$. Charles Hull ise; 1986 yllında, 3 boyutlu nesnelerin üretilmesi için, stereolitografi tekniğinin patentini almıştır (6). Hull, aynı yıl 3D sistemler şirketini kurmuştur ve Standart Mozaikleme Dili (Standard Tessellation Language, STL) dosya formatını geliştirmiştir (7).

STL, CAD yazılımı ile 3 Boyutlu yazıcılar arasında veri aktarımı için kullanılan dosya formatıdır. Dosya formatı katı modellerin yüzeyini üçgenlerle ifade eder. "Stereolitograpy Apparatus" diye adlandırılan ilk yazıcıdan sonra; 1988 yılında 3D sistemler şirketi, SLA-250 adını verdikleri ticari olarak ulaşılabilir ilk 3 boyutlu yazıcıyı tanıttılar (7). 1989 ylında Scott Crump eriyik yığma modelleme metodu ile üç boyutlu nesneler oluşturmak için bir cihazın patentini aldı $(7,8) .1991$ yılında stereolitografi tekniğiyle ilk medikal uygulama Viyana'da, maksillofasiyal cerrahi kliniğinde tanitıldı (9). 1993 yılında Massachusetts Institute of Technology (MIT), 2 boyutlu yazıcılardaki inkjet teknolojisini kullanarak yeni bir teknoloji geliştirdi ve buna 3 boyutlu yazıcı adı verildi $(7,10)$. Adrian Bowyer, 2005 yılında kendi kendini kopyalayan Replicating Rapid (REPRAP)'1 icat etti $(11,12)$. REPRAP; kendi bileşenlerini oluşturabilen, genel amaçlı üretime olanak veren ilk 3 boyutlu yazıcıdır (12).

Kabaca tanımlarsak; 3 boyutlu baskı, sanal ortamda tasarlanmış 3 boyutlu bir nesnenin katı formda basılması işlemidir. Baskı işlemini gerçekleştiren cihazlara da 3 boyutlu yazıcılar denir. 3 boyutlu baskıda (teknik adıyla eklemeli üretim teknolojisi), birleştirme işlemi genellikle katman üzerine katman eklenerek gerçekleştirilir. Aşındırıcı üretim teknolojisinden temel farkı budur (13).

\section{ÜRETIM TEKNOLOJILERI}

\section{Aşındırıcı Üretim ve GAD GAM Gelişimi}

Aşındırıcı üretim; istenilen geometriyi elde etmek için torna, matkap, frez, testere gibi kesici takımların kullanıldığı imalat yöntemidir. CAD/CAM de bir aşındırıcı üretim yöntemidir. CAD/CAM'de tasarım ve üretim bilgisayar kontrolüyle olur. Üretim malzeme bloğuyla başlar ve makine istenmeyen parçaları kesip atar. CAD/CAM sistemleri; veri toplama, veri işleme ve imalat aşamalarından oluşmak- tadır. Kapalı sistemlerde; tarayıcı, yazılım ve donanım üniteleri bir arada bulunmaktadır ve üretim işlemleri sırasında seçim yapılması olanaksızdır. Açı sistemlerde ise durum tam tersidir. Açık sistemler, farklı donanımlar arasında ve farklı üretim merkezleri arasında seçim yapma şansı sunar. Açık sisteme geçiş, diş hekimliği pratiğinde önemli bir adım olmuştur. Çünkü açık sistemlerin kullanılmasıyla intraoral tarayıcı, model sayısallaştırıcı (tarayıcı), manyetik rezonans görüntüleme (MRG), ultrasonografi (USG) ve bilgisayarlı tomografi (BT) kaynakları kullanılarak veri toplama açısından esneklik sağlanmıştır (14).

\section{Eklemeli Üretim (3 Boyutlu Yazıcılar)}

Eklemeli üretim, Amerikan Test ve Malzeme Kurumu (American Society for Testing and Materials) tarafindan şöyle tanımlanmıştır: " 3 boyutlu model verilerinden cisimler oluşturmak için kullanılan, katman üstüne katman şeklinde aşındırıcı üretim metodolojilerinin tam aksi olarak malzemelerin birleştirilmesi işlemidir." (13).

3 boyutlu yazıcı ile üretim süreci Şekil l'de gösterilmiştir (15).

\section{Eklemeli Üretim Teknolojileri}

\section{a. Stereolitografi}

Stereolitografi (SLA) ilk defa 1986 yilında Charles W. Hull tarafindan şöyle tanımlanmıştır: "Ultraviyole (UV) ışınla sertleşen bir materyalin birbiri üzerine ince tabakalar halinde yığılmasıyla katı objelerin yapılması metodudur “. SLA ile üretim UV lazerin fotoreaktif reçineyi ince katmanlar halinde dondurmasyyla olur (14). SLA tekniğinde reçineyle dolu olan kazan içerisinde hareket edebilen bir tabla vardır. Tabla polimerize edilecek olan reçinenin hemen altında yer alır. Bilgisayarla kontrol edilen lazer ile sıvı reçine polimerize olduktan sonra yeni katmanların oluşturulması için tabla katman kalınlığı kadar aşağı iner (16). UV lazer her katmanı ortalama 1-2 dakika tarar (14). Model tamamlanana kadar bu işlem devam eder. İşlem bittiğinde, model üzerinde kalan artık parçalar temizlenir ve firına konur (16). Bir çalışma ortalama 6 -12 saat sürer, büyük nesnelerin üretimi ise birkaç gün sürebilir (14).

\section{b. Dijital Işık İşleme}

Dijital Işık Işsleme'de, SLA'ya benzer bir üretim süreci vardır. SLA gibi yüksek çözünürlükte parçalar üretilebilir. Kullanılan materyaller aynıdır fakat SLA' da lazer ışını kullanılırken, dijital ışık işlemeli yazıcılarda görünür ışık kullanılır. Bu teknikte süreci hızlandırmak için SLA'da kullanılan kazana göre daha sığ bir kazan kullanılır. Bunun sonucu olarak da SLA'ya göre daha az atık oluşur (17).

\section{c. Lazer Tozu Şekillendirme}

Seçici lazer eritme (SLE) ve seçici lazer sinterleme (SLS) gibi lazer bazlı üretim tekniklerinde katı obje oluşturmak 


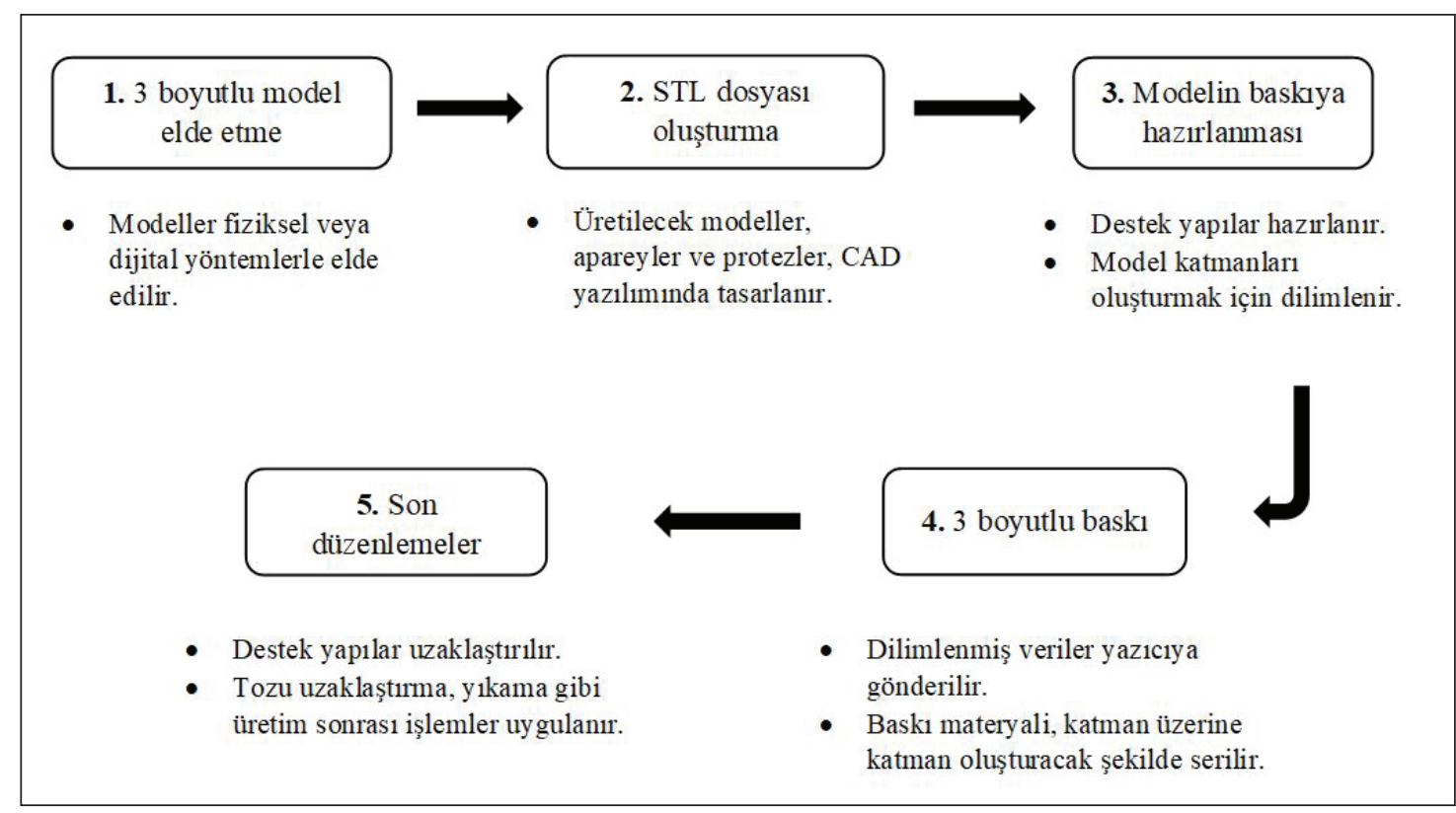

Şekil 1: 3 boyutlu yazıcılar ile üretim süreci.

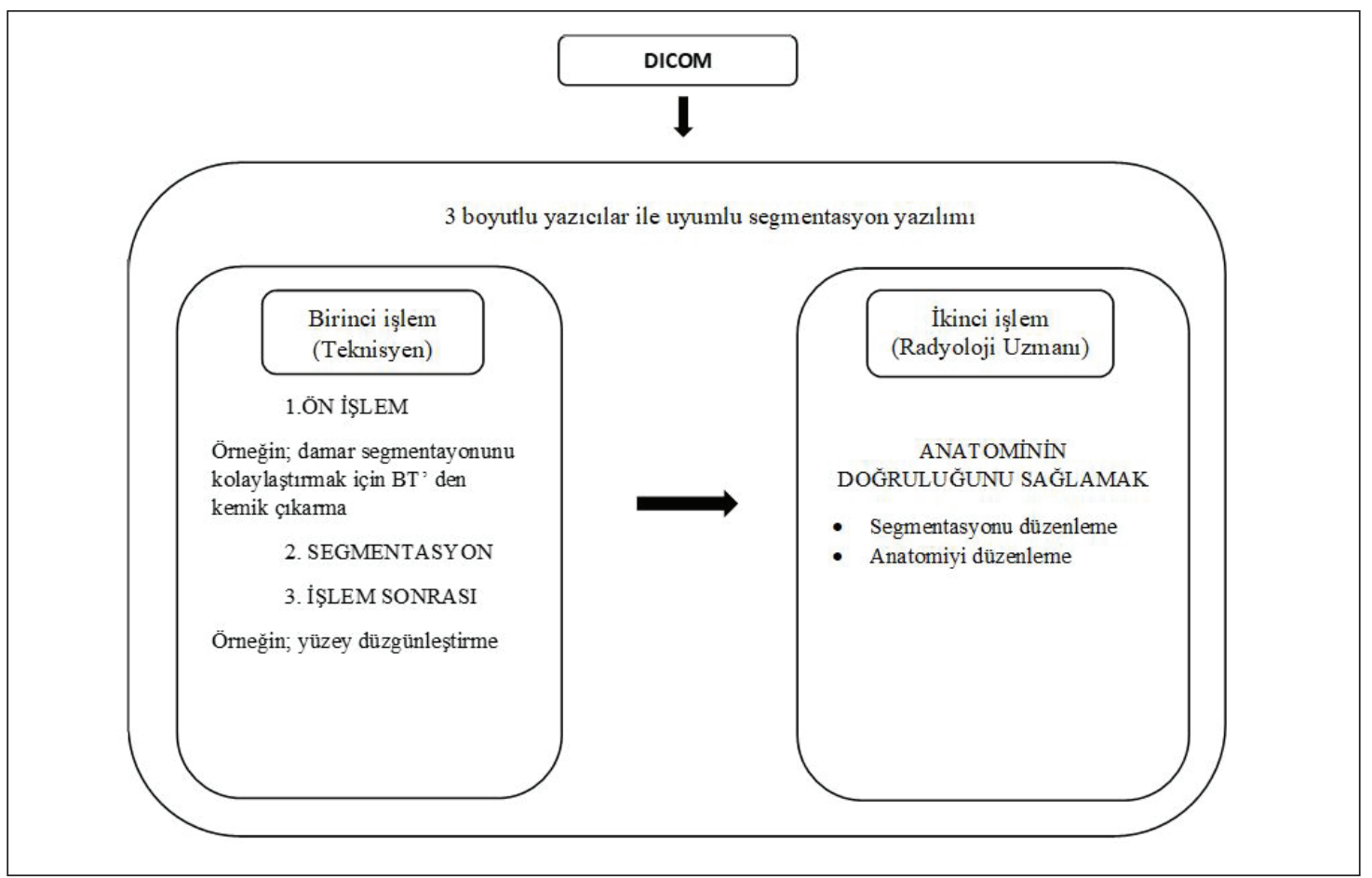

Şekil 2: Tasarım aşamasında radyoloji.

için substrat olarak kullanılan toz halindeki materyale lazerin aynalar aracılığıyla yönlendirilmesi esastır (14). Lazer ışınının yüzeye çarpmasıyla oluşan ısı, tozu istenilen şekilde bir araya getirir ve CAD verilerinden 3 boyutlu parçalar oluşturur. Sistemde bulunan toz tabakanın hemen altında hareketli bir platform mevcuttur. Tarayıcı sistem aracılı̆̆ıyla belirlenen bölge tarandıktan sonra, ilk katman oluşturulur ve yeni katmanların oluşması için platform, katman kalınlığı kadar aşağı iner. İşlem tamamlanıp solid nesne oluşana kadar işlem tekrarlanır. Sinterleme işlemi tamamlandıktan sonra istasyonun biraz soğuması beklenir.
Üretilen parça, firçalar ve vakumlu süpürgelerle tozlardan arındırılır. Bu yazıcılarla sinterlenen tozun dışında kalan toz destek görevi gördüğü için ek bir destek materyaline ihtiyaç yoktur (16). Lazer sinterleme ile detaylı ve hassas yapilar oluşturulabilir. Detay derecesi lazerin hassasiyeti ve tozun inceliğine bağlıdır. Lazer tozu şekillendirme ile metal, plastik ve seramik objeler üretilebilir (18). Üretimde polimer veya seramik kullanılacaksa genellikle SLS kullanımı tercih edilirken metal kullanılacaksa SLE veya direkt metal lazer sinterleme (DMLS) kullanılır (14). Üretilen nesnelerin tekrardan kürlenme (sertleştirilme) gibi bir ihtiyacı yoktur (16). 


\section{d. Elektron Işınlı Eritme}

Elektron ışınlı eritme (EBM), metal parçaların üretiminde kullanılan eklemeli imalat teknolojilerindendir. Bu teknolojide elektron demeti; yüksek vakum altında metal tozunu katman katman eritir ve yoğun bir bileşen oluşturur. Elektronların akımı, volfram filamentinin isıtılması yoluyla oluşturulur ve daha sonra elektron demeti manyetik alan kullanılarak yönlendirilir. Eritilecek her katman CAD modeliyle tanımlanan geometriyle eritilir. Diğer metal sinterleme tekniklerinin aksine parçalar tam yoğun, boşluksuz ve son derece güçlüdürler (14).

\section{e. Eriyik yığma modelleme (EYM, FDM, Fused Depositing Modelling)}

EYM yazıcılarda; plastik, granül ya da tel filament gibi termoplastik materyaller kullanılır. Bu yazıcıların çalışma prensibi şöyledir: Solid nesneyi oluşturacak plastik ya da metal materyal akışı için açıp kapanabilen bir ekstrüzyon başlığına yönlendirilir. Başlık termoplastik materyali erime noktasının hemen üzerindeki sıcaklıkta tutar. Başlık ısıtılır ve yazılım paketi tarafindan sayısal olarak kontrol edilen mekanizma ile hem yatay hem dikey yönde hareket ettirilir. Küçük damlaların ağızlıktan çıkar çıkmaz donması ile tabaka oluşur. İlk katmanın tamamlanmasından sonra platform aşağı hareket eder ve ekstrüzyon başlı̆̆ı diğer katmanı inşa eder. Bu yöntemde model üretilirken destek malzemesi kullanılır ve destek malzemesi kullanabilmek amacıyla sisteme ikinci bir ekstrüzyon başlı̆̆ı ilave edilmiştir (16).

\section{f. Yapıştırıcı ile Katmanlı İmalat (Binder jetting, powder binder)}

$\mathrm{Bu}$ yöntemde toz materyal ve tozu birleştirmek için yapıştırıcı kullanılır (19). Silindir ile serilen toz materyal üzerine mürekkepli yazıcılar benzeri hareketli bir başlık ile yapıştırıcı uygulanır. Platform katman oluştukça aşağı iner ve obje oluşana kadar bu döngü devam eder (20). Destek yapıya ihtiyaç yoktur. Bağlayıcıya çeşitli renkler eklenebilir (19).

\section{g. Malzeme Püskürtme (Material jetting, inkjet)}

Malzeme püskürtme ile eklemeli üretim tekniği; inkjet 3 boyutlu yazıcı olarak da bilinir (21). Bu yazıcılarla 3 boyutlu modeller, mürekkep püskürtmeli yazıcılardaki tekniğge benzer bir şekilde üretilir (20). Teknik şöyledir; piezoelektrik başlık sıvı fotopolimer damlacıkları püskürtür ve UV lambalar, fotopolimeri hemen sertleştirir (21). Piezoelektrik başlık hareketli platformun üzerinde konumlandırılır. İlk katman tamamlandıktan sonra platform aşağıya iner ve diğer katman inşa edilir. Bu işlem model bitene kadar tekrarlanır (20). Inkjet 3 boyutlu yazıcılarda (örneğin MultiJet), aynı anda çok parçalı nesneler imal etmek için çeşitli rezinler kullanılabilir. Destek yapı otomatik olarak üretilir (21).

\section{Eklemeli Üretimin Avantajları ve Dezavantajları Avantajları}

Eklemeli üretim teknolojisinin geleneksel üretim yöntemlerine göre sayısız avantajları vardır.

- Tasarım esnekliği: Eklemeli üretim; geleneksel yöntemlere göre, karmaşık geometrik özelliklere sahip parçaların üretiminde daha iyidir. Daha az malzeme kullanılarak, daha iyi tasarımlarla, çeşitli özellikte nesnelerin üretimine olanak sağlar.

- Üretim esnekliği: Eklemeli üretimin, üretim açısından bize sunduğu önemli özelliklerden birisi; dijital ortamda yapılan tasarım aşamasında değişiklik yapmanın kolay olmasıdır. Karmaşık parçalar tek parça halinde basılabilir. Ayrıca cihazın kurulumu ve montajı kolaydır.

- Kaynak verimliliği: Eklemeli üretim, ana makinaya ek olarak yardımcı parçalara ihtiyaç duymaz. Konvansiyonel üretimde ise kalıp, kesici gibi yardımcı parçalara ihtiyaç vardır. Ayrıca eklemeli üretimde nakliye ve stoklara daha az ihtiyaç vardır. Elektronik postayla yollanan veriler ile istenildiği zaman baskı alınabilir. Tüm bu durumlar masrafin azaltılmasını sağlar.

- Malzeme verimliliği: Aşındırıcı üretimde, büyük miktarda materyal kaldırılması gerekir. Eklemeli üretimde ise gerektiği kadar malzeme kullanılır, hammadde verimli bir şekilde kullanılır. Materyal israfı yoktur. $(22,23)$

\section{Dezavantajları}

- Boyut sınırlamaları: Eklemeli üretim süreçleri katmanlar oluşturmak için, sık sık sıvı polimerler ya da reçine ve alçıdan oluşan bir toz katman kullanır. $\mathrm{Bu}$ materyaller, mukavemet eksikliğinden dolayı, 3 boyutlu yazıcıların büyük ölçekli nesneleri üretememesine neden olur. Uzun zaman gerektiği için, büyük boyutlu nesnelerin üretiminde kullanılması genelde pratik değildir.

- Kusurlar: Eklemeli üretim ile imal edilen parçaların yüzeyleri pürüzlüdür. Üretimden sonra parça bitmemiş gibi görünmektedir, bu yüzden bazı tekniklerde üretim sonrası ek işlemler gerekmektedir.

- Maliyet: 3 boyutlu yazıcılar, ekipmanlar ve kullanılan materyaller pahalıdır. Günümüzde bu yazıcıların en ucuzu 5000 dolardan başlar. Yüksek kaliteli modeller için; aksesuar, reçineler ve diğer işletme malzemeleri maliyeti hariç olmak üzere, fiyatlar 50.000 dolara kadar çıkabilir. $(22,23)$

3 boyutlu yazıcılarla üretimde kullanılan tekniklerin de birbirlerine göre farklılıkları bulunmaktadır. Tekniklerin avantaj ve dezavantajları Tablo I'de gösterilmiştir $(15,19,24)$. 
Tablo I: Tekniklerin avantaj ve dezavantajları

\begin{tabular}{ll}
\hline Teknik & Avantajlar \\
\hline Stereolitografi & Çözünürlügü yüksek, karmaşı parçaları \\
(SLA) & oluşturmak mümkündür. \\
& Toplu olarak kullanılırsa düşük \\
& maliyetlidir. \\
& • Üretilen parçaların yüzeyi düzgündür. \\
& Imalat hızlıdır, fonksiyonel parçalar bir \\
& günde üretilebilir.
\end{tabular}

\section{Dezavantajlar}

- Seri üretim için kullanılamaz.

- Üretilen Parçalar kırılgandır.

- Sadece ışıkla sertleşebilen sıvı polimerlerle üretim mümkündür.

- Yüksek maliyetli bir teknolojidir.

- Destek malzemeleri çıkarılması zordur.

- Her model için sadece bir çeşit materyal kullanilabilir.

\begin{tabular}{|c|c|c|}
\hline $\begin{array}{l}\text { Malzeme püskürtme } \\
\text { (Inkjet yazıcılar) }\end{array}$ & $\begin{array}{l}\text { - Karmaşık parçalar yazdırılabilir. } \\
\text { - Üretim hızlıdır. }\end{array}$ & $\begin{array}{l}\text { - Makine maliyeti yüksektir. } \\
\text { - Üretilen nesneler için boyut sinırlaması } \\
\text { vardır. }\end{array}$ \\
\hline
\end{tabular}

\begin{tabular}{llll}
\hline Dijital ışık işleme & - Nispeten hızlıdır. & $\bullet$ & Döküm için işıkla sertleşen polimerler ve \\
& - Düşük maliyetli bir teknolojidir. & mum benzeri materyaller kullanılır. \\
& • Üretilen parçaların yüzeyi pürüzsüzdür. & $\bullet$ & Destek malzemeleri çıkarılmalıdır. \\
& & $\bullet$ & Kullanılan malzemeler pahalıdır.
\end{tabular}

Yapıstıcı ile katmanlı imalat • Kullanılan teknoloji ve malzemeler düsük • Üretilen parçaların cözünürlüğü düsüktür (Binder jetting) maliyetlidir.

- Renkli yazdırmak mümkündür.

- Karmaşık şekilli nesneler basılabilir.

- Malzemeler güvenlidir.

- Destek yapı gerektirmez.

Seçici lazer sinterleme (SLS)

(Polimerler için)

- Naylon, elastomer ve kompozitler dahil olmak üzere polimer malzeme yelpazesi geniştir.

- Üretilen parçalar serttir ve dayanıklıdır.

- Destek yapıya ihtiyaç yoktur.

- Üretilen parçaların kimyasal dayanımı yüksektir.

- Tam mekaniksel işlevselliğe sahip parçalar üretilebilir.

- Üretilen parçalar ıslatılamaz ve isı ile sterilize edilemezler.

- Üretimde sadece bir çeşit materyal kullanilabilir.

- Üretilen parçaların yüzeyi kabadır.

- Alt yapı gereklidir. Örneğin; basınçlı hava, hava kontrolü.

- Yüksek maliyetli bir teknolojidir.

- Üretilen parçaların yüzeyi gözeneklidir.

- Parçaların yüzeyine Siyanoakrilat gibi kaplama materyali uygulanir.

- Üretilen parçalardan tozu uzaklaştırmak oldukça zordur.

- Titanyum, titanyum alaşımları, krom, kobalt, paslanmaz çelik gibi çeşitli malzemeler kullanılabilir.

Seçici lazer sinterleme (SLS)

(Metal ve metal alaşımları için) (SLE/DMLS)
- Ince detayları oluşturmak mümkündür.

- Üretilen parçalar dayanıklıdır.

- Karmaşık şekilli ürünler üretilebilir.
- Son derece pahalı bir teknolojidir.

- Toz ve nanoparçaçık yoğunlaşması sağlığa zararlı olabilir.

- Kullanılan malzemeye bağlı olarak yüzey gözenekli ve kaba olabilir.

- Üretilen parçalar eğilip, büzülebilir.

- Üretim sonrası iç gerilimleri gidermek için ssil işlem gereklidir.

- Destek malzemeleri çıkarmak zordur.

- Teknoloji son derece pahalıdir.

- Toz sağlığa zararlı olabilir.

- Üretilen parçalar kaba yüzeylidir.

- Üretilen parçaların çözünürlüğü düşüktür. Bu teknoloji ile üretim sırasında x-1şını salınımı olur.
Elektron 1şınlı ergitme (EBM)
- Dar açılı ışınla yüksek enerji seviyesine ulaşlır.

- Üretilen parçalar boşluksuz ve yoğundur.

- Üretim yüksek sıcaklıkla olur bu yüzden sonrasında isl işlem gerektirmez.

- Vakum ortamdaki artıkları ortadan kaldırır.

- Güç tüketimi azdır. 
Tablo I: Devam

\begin{tabular}{|c|c|c|}
\hline Teknik & Avantajlar & Dezavantajlar \\
\hline $\begin{array}{l}\text { Eriyik yığma modelleme } \\
(\text { EYM, FDM })\end{array}$ & $\begin{array}{l}\text { - Düşük maliyetli bir teknolojidir. Üretilen } \\
\text { - } \text { Parçalar dayanıklıdır. } \\
\text { - } \quad \text { Bu yazılar farklı renklerde basılabilir. } \\
\text { veya esnek malzemellerin üretimde sert }\end{array}$ & 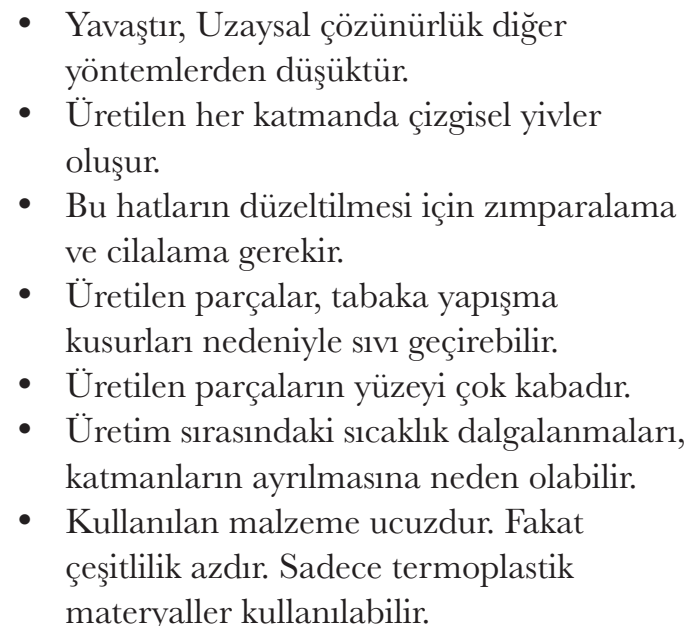 \\
\hline
\end{tabular}

3 Boyutlu Yazıcıların Diş Hekimliği Pratiğinde Kullanım Alanları

\section{a. Eğitim}

Tıp eğitiminde, klinik beceriyi geliştirmek için kullanılan kaynaklara ulaşmak önemli sorunlardan biridir. Özellikle eğitim amaçlı kullanılmak üzere ihtiyaç olan insan dokusunun elde edilmesi; bazı ülkelerde ve kültürel ortamlarda, tıp eğitimcileri için ciddi problemler yaratmaktadır. Ancak modern teknoloji, kaynaklara ulaşmak için yeni çözümler sunmaktadır (25). Teknolojinin bizlere kazandırdığı 3 boyutlu yazıcılar, eğitimde değerli bir kaynak olabilecek yenilikçi bir yaklaşım olarak değerlendirilebilir. 3 boyutlu yazıcılarla, ucuz ve kolay bir şekilde anatomik modeller üretilebilir ve bu modeller, karmaşı anatomik yapıların kolayca öğrenilmesi için kullanılabilir (26). AbouHashem ve arkadaşları yaptıkları çalışmada; mevcut kemikler taranarak 3 boyutlu yazıcılarla üretilen kemiklerin, Macquarie Üniversitesi ve Batı Sidney Üniversitesi'nde anatomi eğitiminde başarılı şekilde kullanıldığını göstermişlerdir (25).

Diş hekimliği preklinik eğitiminde ise, yaygın olarak çekilmiş dişler kullanılmaktadır. Ancak, öğrencilerin yeterli sayıda çekilmiş dişe ulaşması oldukça zordur. Cantín ve arkadaşları; diş hekimliği öğrencilerinin, kolayca öğrenmelerini sağlayacak eğitim materyallerini sunmak amacıyla, çekilmiş dişleri tarayarak sanal ve basılmış dişler ürettiler. Böylece 3 boyutlu yazıcılarla üretilen dişlerin çekilmiş ya da plastik dişler yerine kullanılabileceğini gösterdiler (27).

\section{b. Oral Gerrahi}

3 boyutlu yazıcılar kullanılarak yapılan anatomik modeller; cerrahi planlama, simülasyon ve hekimler arası konsültasyon için kullanılabilir. 3 boyutlu modeller; cerrahın, ameliyat öncesinde karmaşık yapılara genel bir bakış elde etmesini sağlar (28).

3 boyutlu yazıcıların sunduğu bir diğer avantaj ise zaman tasarrufudur. Yapılan bir çalışmada; mandibula rekonstrüksiyon plaklarının, ameliyattan önce 3 boyutlu yazıcılar ile üretilen modellerle bükülmesinin, anlamlı derecede çalışma süresini kısalttığı gösterilmiştir (29).

$\mathrm{Bu}$ yazıcıların cerrahideki bir diğer kullanım alanı ise, bu teknoloji ile cerrahi kılavuzların üretilebilmesidir (24). Liu ve arkadaşlarının yaptığı bir çalışmada, mandibula rekonstrüksiyonu için 3 boyutlu planlama ve üretim teknolojilerinden faydalanılmıştır. Üretilen cerrahi kılavuzların kullanımıyla ameliyat zamanından tasarruf edilmiştir ve ameliyatın mandibular rekonstrüksiyon üzerindeki etkisini iyileştirdiği kanıtlanmıştır (30).

\section{c. Dental İmplantoloji}

3 boyutlu yazıcılarla; tam yoğunluklu, dayanıklılığı yüksek, yeterli boyutsal doğruluğu olan, kişiye özel implantlar üretilebilir (31). 3 boyutlu yazıcılarla üretilen implantlar klinik uygulamada başarılıdır (32). Chen ve arkadaşları tarafindan yapılan bir çalışmada; BT görüntüsü ile tasarlanıp basılan dental implantın, taze çekim soketine implantasyonundan sonra yapilan takiplerde, implant ile çevre doku arasında bir uyumsuzluk olmamıştır. Ayrıca herhangi bir radyolüsensi de görülmemiştir (32).

Diğer bir kullanım alanı ise, cerrahi implant kılavuzlarının üretimidir. Klinik veriler; bilgisayar destekli 3 boyutlu üretilen cerrahi kılavuzların, implant yerleştirilmesinde yararlı olabileceğini göstermiştir (33). Yapılan bir çalışmada; dental implantların uygulanması için kullanılan cerrahi implant kllavuzlarının, 3 boyutlu yazıcılarla üretiminin pratik bir seçenek olduğu kanıtlanmıştır (34). 


\section{d. Protetik Diş Tedavisi}

Hasta modelleri, ağız içi doku ve dişlerin detaylarını yansıtan araçlardır. Geleneksel yöntemde; çeşitli ölçü maddelerini kullanarak, protez kaşığı ile ağız içinden aldığımız ölçüyle model elde ederiz. Teknolojinin gelişmesiyle birlikte, geleneksel yöntemlerde değişimler başlamıştır ve üretimde 3 boyutlu yazıcı teknolojisinin kullanılmasıyla, kişisel ölçü kaşıklarının ve modellerin üretilmesi mümkün olmuştur. Chen ve arkadaşlarının yapmış olduğu bir çalışmada; el yapımı kişisel ölçü kasıklarına kıyasla, 3 boyutlu yazıcı ile yapılan kişisel ölçü kaşılarının doğruluğu daha yüksek bulunmuştur (35). 3 boyutlu yazıcılar ile üretilen modeller üzerinde yapılan bir çalışmada ise, modellerin doğruluk oranın yüksek olduğu gösterilmiştir (36).

3 boyutlu yazıcıların başarısını kanıtladı̆̆ı diğer bir kullanım ise, geçici kron köprü protezlerinin üretilmesi olmuştur. Bu teknoloji ile, dakikalarla ifade edilen kısa zaman dilimlerinde geçici kron köprü protezlerinin üretimi gerçekleşmiştir (37).

Geleneksel yöntemlerle metal döküm işlemi oldukça uzun ve zahmetlidir. Alçı modeller üzerine yapılan mum modelajdan sonra, mumun yerini metalin alması için bir dizi işlemler zinciri uygulanır. CAD/CAM ile metal alt yapı üretimi biraz daha hız kazanmıştır. Gelişen ve yenilenen üretim teknolojisi ile birlikte 3 boyutlu yazıcılar, hareketli ve sabit bölümlü protezlerdeki metal alt yapının üretimine olanak tanımıştır. Yapılan bir çalışmada; sabit ve hareketli bölümlü protezlerin metal alt yapısının üretilmesinde 3 boyutlu yazıcıların, diğer üretim yöntemlerine göre daha hızlı ve ucuz olduğu gösterilmiştir (38). Ayrıca 3 boyutlu yazıcıların diğer bir kullanım alanı ise bruksizm için kullanılan okluzal splintlerin üretilmesi olmuştur (39).

\section{e. Ortodonti}

Ortodontide genellikle alçı modeller tercih edilmektedir. Çünkü bu modeller; teşhis, tedavi ve diğer hekimlerle konsültasyon açısından daha pratiktir (40). Fakat dijital modellerin alçı modellere göre üstün yönleri vardır. Depolama, bilgiye tekrardan ulaşım ve bilgiyi aktarım kolaylı̆̆ı, dijital modellerin sunduğu avantajlardandır. Veriler, dijital modellerin ortodontik kayıtlarda başarılı olduğunu göstermiştir (41). Ortodontik hareketli apareyler ve braketlerin yerleştirilmesine rehber olan plaklar da, 3 boyutlu yazıcılarla üretilebilir (42). Yapılan bir çalışmada; 3 boyutlu yazıcı- larla üretilen ve indirekt braket yerleştirilmesinde kullanılan plakların, braketlerin daha kısa zamanda ve doğru şekilde yerleştirilmesini sağlayarak, klinisyene yardımcı olabileceği gösterilmiştir (43). Ortodontide başarısını kanıtladığı bir diğer alan ise aligner olarak adlandırdığımız, hareketli ve şeffaf ortodontik hizalayıcıların üretimi olmuştur. Bu hizalayıcıların; 3 boyutlu yazıcılarla, günlük ortalama 50.000 tane üretilebilmesi ticari bir başarıdır (44).

\section{f. Radyoloji}

Radyolojik görüntülerden yararlanılarak yapılan 3 boyutlu üretim multidisiplinerdir. İleri görüntüleme yöntemleri kullanılarak üretilen, hasta anatomisini ve patolojik süreçleri gösteren tam doğru modellerin tasarlanıp üretilmesi için, radyologlar ve klinik hekimleri arasında yakın etkileşim gereklidir.

Anatomik parçaların 3 boyutlu yazım akışı şöyle ilerlemektedir; başlangiçta tıp için geliştirilmiş Tıpta Dijital Görüntüleme ve İletişim (Digital Imaging and Communication in Medicine, DICOM) uzantılı görüntüler, uyumlu bir segmentasyon yazılımı ile işlenir. Segmentasyon, görüntüden bölümler oluşturmaktır. Sonrasında bölümlere ayrılmış anatomi, radyolog tarafindan gözden geçirilir. DICOM verileri STL formatına dönüştürülür. STL dosyasında tanımlanan anatomik parçalar 3 boyutlu yazdırılabilir (45). Radyoloji uzmanları ve teknisyenlerinin tasarım aşamasındaki görevleri Şekil: 2'de gösterilmiştir (45).

\section{SONUÇ}

Veriler 3 boyutlu yazıcı endüstrisinin hızla gelişmekte olduğunu göstermektedir (46). Teknolojik gelişmelerle birlikte üretim teknolojilerine dahil olan 3 boyutlu yazıcılar, sağlık alanıyla birlikte diş hekimliği pratiğine de yeni bir vizyon kazandırmıştır. Zengin renk, materyal ve üretim yelpazesine sahip olan diş hekimliği pratiğinin, 3 boyutlu yazıcılarla birlikte daha hızlı ve kaliteli üretime kavuşacağı aşikardır. 3 boyutlu yazıcılar, aşındırıcı üretimin birçok dezavantajını ortadan kaldırmıştır ve sunduğu kolaylıklarla gelecek için ümit vericidir. Diş hekimliğinin her alanında kullanılmaya başlanan 3 boyutlu yazıcıların, yakın bir gelecekte yeni ve farklı kullanım alanlarının oluşmasına ve her geçen gün bu alanların genişlemesine tanık olacağız. 3 boyutlu yazıcılarla üretim, diş hekimliği pratiğinin büyük bir kısmında devrim yaratacaktır. 


\section{KAYNAKLAR}

1. Özsoylu AF. Endüstri 4.0. Çukurova Üniversitesi Iktisadi ve İdari Bilimler Fakültesi Dergisi 2017; 21(1): 41-64.

2. Raicu L, Marin, D. Design aspects in machine tools evolution. Journal of Proceedings of The International Conference on Manufacturing Systems; 2008; 3: 59-64.

3. Duret F, Preston JD. CAD/CAM imaging in dentistry. Current Opinion in Dentistry 1991; 1: 150-154.

4. Kodama H. Automatic method for fabricating a three-dimensional plastic model with photo-hardening polymer. Review of Scientific Instruments 1981; 52(11): 1770-1773.

5. Bhusnure OG, Gholve VS, Sugave BK, Dongre RC, Gore SA, Giram PS. 3D printing and pharmaceutical manufacturing opportunities and challenges. International Journal of Bioassays 2016; 5(1): 4723-4738.

6. Hull, Charles W. "Apparatus for production of threedimensional objects by stereolithography." United States Patent, Appl., No. 638905, Filed 1984.

7. Gross BC, Erkal JL, Lockwood SY, Chen C, Spence DM. Evaluation of 3D printing and its potential impact on biotechnology and the chemical sciences. Anal Chem 2014; 86(7): 3240-3253.

8. Crump SS. U.S. Patent No. 5,121,329. Washington, DC: U.S. Patent and Trademark Office 1992.

9. Lindner A, Rasse M, Wolf HP, Millesi W, Eglmeier R, Friede I. Indications and use of stereolithographic skull reconstructions in oromaxillofacial surgery. Der Radiologe 1995; 35(9): 578-582.

10. Sachs EM, Haggerty JS, Cima MJ, Williams PA. Threedimensional printing techniques. U.S. Patent 5,204,055, April 20, 1993.

11. Artuğa S, Altun MC. 3 boyutlu bask1 teknolojisinin bina üretiminde kullanım olanaklarının güncel örnekler üzerinden incelenmesi. In, Çetinkaya $\mathrm{K}$, Duman B, Özsoy K, Kayaalp K, Oral O, Aydın M, editors. 4th International Congress on 3D Printing (Additive Manufacturing) Technologies and Digital Industry; 2019 April 11-14; Antalya. Turkey; 2019. p: 118-132

12. Jones R, Haufe P, Sells E, Iravan P, Oliver V, Palmer C, Bowyer A. RepRap-the replicating rapid prototyper. Robotica 2012; 29(1): 177-191.

13. Astm, I. S. O. ASTM52900-15 Standard Terminology for Additive Manufacturing-General Principles-Terminology. ASTM International, West Conshohocken, PA, 2015; 3(4): 5 .

14. Van Noort R. The future of dental devices is digital. Dental Materials 2012; 28(1): 3-12.

15. Dawood A, Marti BM, Sauret-Jackson V, Darwood A. 3D printing in dentistry. British Dental Journal 2015; 219(11): 521.
16. Çelik İ, Karakoç F, Çakır MC, Duysak A. Hızh prototipleme teknolojileri ve uygulama alanları. Dumlupınar Üniversitesi Fen Bilimleri Enstitüsü Dergisi 2013; 031: 53-70.

17. Jasveer S, Jianbin X. Comparison of different types of 3D printing technologies. International Journal of Scientific and Research Publications 2018; 8(4): 1-9.

18. Hoy MB. 3D printing: Making things at the library. Medical Reference Services Quarterly 2013; 32(1): 93-99.

19. George E, Liacouras P, Rybicki FJ, Mitsouras D. Measuring and establishing the accuracy and reproducibility of 3D printed medical models. Radiographics 2017; 37(5): 14241450.

20. Yalçın B, Ergene B. Endüstride yeni eğilim olan 3-d eklemeli imalat yöntemi ve metalurjisi. Uluslararası Teknolojik Bilimler Dergisi 2017; 9(3): 65-88.

21. Yap YL, Wang C, Sing SL, Dikshit V, Yeong WY, Wei J. Material jetting additive manufacturing: An experimental study using designed metrological benchmarks. Precision Engineering 2017; 50: 275-285.

22. Jasiuk I, Abueidda DW, Kozuch C, Pang S, Su FY, McKittrick J. An overview on additive manufacturing of polymers. The Journal of The Minerals 2018; 70(3): 275283.

23. Huang SH, Liu P, Mokasdar A, Hou L. Additive manufacturing and its societal impact: a literature review. The International Journal of Advanced Manufacturing Technology 2013; 67(5-8): 1191-1203.

24. Javaid M, Haleem A. Current status and applications of additive manufacturing in dentistry: A literature-based review. Journal of Oral Biology and Craniofacial Research 2019; 9(3): 179-185

25. AbouHashem Y, Dayal M, Savanah S, Štrkalj G. The application of 3D printing in anatomy education. Medical Education Online 2015; 20(1): 29847.

26. Vaccarezza M, Papa V. 3D printing: A valuable resource in human anatomy education. Anatomical Science International 2015; 90(1): 64-65.

27. Cantín M, Muñoz M, Olate S. Generation of 3D tooth models based on three-dimensional scanning to study the morphology of permanent teeth. International Journal of Morphology 2015; 33(2): 782-7.

28. Aydın N, Kaya İ, Hüsemoğlu RB, Arslantaş A. Torakal vertebra görüntülemesinde simülasyon ve üç boyutlu modellemenin radyolojik tanı ve cerrahi öncesi planlama üzerinde etkileri. Osmangazi Tip Dergisi 2017; 39(3): 58-61.

29. Hanasono MM, Skoracki RJ. 117B: Improving the speed and accuracy of mandibular reconstruction using preoperative virtual planning and rapid prototype modeling. Plast Reconstr Surg 2010; 125(6): 80. 
30. Liu YF, Xu LW, Zhu HY, Liu SSY. Technical procedures for template-guided surgery for mandibular reconstruction based on digital design and manufacturing. Biomedical Engineering Online 2014; 13(1): 63.

31. Chen J, Zhang Z, Chen X, Zhang C, Zhang G, Xu Z. Design and manufacture of customized dental implants by using reverse engineering and selective laser melting technology. J Prosthet Dent 2014; 112: 1088-1095.

32. Figliuzzi M, Mangano F, Mangano CA. Novel root analogue dental implant using CT scan and CAD/CAM: Selective laser melting technology. Int J Oral Maxillofac Surg 2012; 41(7): 858-862.

33. Giacomo GAD, Gury PR, de Araujo NS, Sendyk WR, Sendyk CL. Clinical application of stereolithographic surgical guides for implant placement: Preliminary results. J Periodontol 2005; 76(4): 503-507.

34. Whitley III D, Eidson RS, Rudek I, Bencharit S. In-office fabrication of dental implant surgical guides using desktop stereolithographic printing and implant treatment planning software: A clinical report. J of Prosthet Dent 2017; 118(3): 256-263.

35. Chen H, Yang X, Chen L, Wang Y, Sun Y. Application of FDM three-dimensional printing technology in the digital manufacture of custom edentulous mandible trays. Scientific Reports 2016; 6: 19207

36. Jeong YG, Lee WS, Lee KB. Accuracy evaluation of dental models manufactured by CAD/CAM milling method and 3D printing method. The Journal of Advanced Prosthodontics 2018; 10(3): 245-251.

37. Li X, Xie B, Jin J, Chai Y, Chen Y. 3D printing temporary crown and bridge by temperature controlled mask image projection stereolithography. Procedia Manufacturing 2018; 26: 1023-1033.
38. Koutsoukis T, Zinelis S, Eliades G, Al-Wazzan K, Rifaiy MA, Al Jabbari YS. Selective laser melting technique of Co-Cr dental alloys: A review of structure and properties and comparative analysis with other available techniques. Journal of Prosthodontics 2015; 24(4): 303-312.

39. Dovramadjiev T, Pavlova D, Bankova A. Creating a 3D model of dental splint for bruxism. Industry 4.02019 ; 4(4): 167-170.

40. Yılmaz DH, Sözer ÖA, Bilgiç F, Küçük EB. Ortodontide kayit: Radyografive model, Journal of Faculty of Dentistry of Atatürk University Supplement 2016; 143-151.

41. Rheude B, Lionel Sadowsky, Ferriera A, Jacobson A. An evaluation of the use of digital study models in orthodontic diagnosis and treatment planning. Angle Orthod 2005; 75(3): 300-304.

42. Kumar A, Ghafoor H. Rapid prototyping: A future in orthodontics. Journal of Orthodontic Research 2016; 4(1): 1 .

43. Ciuffolo F, Epifania E, Duranti G, De Luca V, Raviglia D, Rezza S, Festa F. Rapid prototyping: A new method of preparing trays for indirect bonding. Am J Orthod Dentofacial Orthop 2006; 129(1): 75-77.

44. Lipson H. New world of 3-D printing offers" completely new ways of thinking": Q\&A with author, engineer, and 3-D printing expert Hod Lipson. IEEE Pulse 2013; 4(6): 12-14.

45. Mitsouras D, Liacouras P, Imanzadeh A, Giannopoulos AA, Cai T, Kumamaru KK, Ho VB. Medical 3D printing for the radiologist. Radiographics 2015; 35(7): 1965-1988.

46. Campbell I, Diegel O, Kowen J, Wohlers T. Wohlers Report 2017: 3D Printing and Additive Manufacturing State of the Industry: Annual Worldwide Progress Report, 22th ed. Fort Collıns, Colorado,USA Wohlers Associates, 2017. 